\title{
Clinical Profile and Outcome of Childhood Tuberculosis at Dhulikhel Hospital
}

\author{
Shrestha $\mathrm{S}^{1}$, Marahatta SB${ }^{2}$, Poudyal $\mathrm{P}^{3}$, Shrestha SM${ }^{4}$
}

${ }^{1}$ Dr. Shrima Shrestha, MBBS, MD, Lecturer, Department of Paediatrics, ${ }^{2}$ Mr. Sujan B Marhatta, MSC, Ph.d. Fellow, Assistant Professor, Department of Community Medicine, ${ }^{3}$ Dr. Prithuja Paudyal, MBBS, Medical Officer, Department of Paediatrics, ${ }^{4}$ Dr. Sujan Makaju Shrestha, Intern, Department of Paediatrics. All from Dhulikhel Hospital, Kathmandu University Hospital, Dhulikhel, Kavre, Nepal.

Address of correspondence: Dr. Shrima Shrestha, E-mail: sima_shrestha@yahoo.com

\begin{abstract}
Background: Children contribute a significant proportion of the tuberculosis (TB) burden in Nepal and suffer severe TB related morbidity and mortality, particularly in endemic areas. Diagnosis and management of pediatric TB especially Extra pulmonary TB (EPTB) is challenging. Objectives: The present study was designed to study clinical, laboratory characteristics and outcome of childhood tuberculosis. Methods: A prospective analysis of 60 cases of TB children within three years period was conducted at Pediatric Department, Dhulikhel Hospital and followed up till child completely recovered. Results: In the present study 60 children had clinical and lab evidence of tuberculosis and received anti tubercular therapy. Extra pulmonary tuberculosis was common (78.3\%) than pulmonary tuberculosis $(21.6 \%)$. BCG scar was absent in eight $(13.33 \%)$ and absent BCG vaccination was significantly associated with disseminated TB $(p<0.05)$. The most frequently seen symptoms were fever $(65 \%)$, cough $(46.67 \%)$ and abdominal distension (36.67\%). Hepatomegaly (45\%), ascites (33.33\%), lymphadenopathy $(23.33 \%)$ and splenomegaly $(11.67 \%)$, and are common signs. Malnutrition seen in (33.3\%) with more malnourished children with disseminated TB than in other diagnosis $(p<0.001)$. Mantoux test was positive in $(48.3 \%)$. Isolation of AFB was possible only in $(8.33 \%)$. Among 60 cases $(60 \%)$ were recovered completely with the primary regimen, $(5 \%)$ recovered with extending the duration of primary regimen to three more months. (25\%) failed to follow up, while $(6.67 \%)$ died. Conclusion: EPTB is common than pulmonary TB. Among 60 cases $36(60 \%)$ recovered completely with the primary regimen, three cases $(5 \%)$ recovered with extending the duration with primary regimen. Fifteen cases $(25 \%)$ failed to follow up, while four cases $(6.67 \%)$ died.
\end{abstract}

Key words: Children, Tuberculosis, Diagnosis, Outcome

\section{Introduction}

$\mathrm{T}$ uberculosis has reemerged as a major public health challenge in the world. Children are mainly infected by adult pulmonary TB source and childhood TB therefore reflects the intensity of the ongoing transmission of Mycobacterium tuberculosis within a community.

It is estimated that one third of the world's population is infected with Mycobacterium tuberculosis, and that each year, about 9 million people develop TB, of whom about 2 million die. Of the 9 million annual TB cases, about 1 million (11\%) occur in children (under 15 years of age). Of these childhood cases, $75 \%$ occur annually in 22 high burden countries that together account for $80 \%$ of the world's estimated incident cases $^{1}$. Despite this huge disease burden, children's access to anti tuberculosis treatment in most endemic areas remains poor, as tuberculosis control programs focus predominantly on the treatment of sputum smearpositive adults ${ }^{2}$. 
Children can present with TB at any age, but the most common age is between 1 and 4 years. Case notifications of childhood TB depend on the intensity of the epidemic, the age structure of the population, the available diagnostic tools, and the extent of routine contact tracing.

\section{Methods}

The prospective study was conducted in the pediatric department of Dhulikhel Hospital, Kathmandu University Hospital from January 2007 to December 2009. All the new cases or diagnosed as tuberculosis from outside and referred for reevaluation in the age group of 0-14 years admitted in the ward with symptoms suggestive of tuberculosis disease were evaluated and diagnosed cases were enrolled into the study. Children were assessed by detail history, thorough physical examination and familial and extra familial contact with TB was enquired, apart from the details of the illness. Mantoux test was done and indurations $\geq 10 \mathrm{~mm}$ after test will be considered a positive reaction. Chest Xray, haemogram and ESR was done in all patients. In relevant cases, sputum for AFB (acid fast bacilli) or in children who cannot expectorate sputum gastric aspirate for AFB smear examination for 3 consecutive days, lymph node biopsy, cerebrospinal, pleural and peritoneal fluid test were done. Confirmed cases were treated according to $\mathrm{WHO}^{1}$ guidance for national tuberculosis programme on the management of tuberculosis in children and IAP consensus on treatment of Childhood ${ }^{4}$ whenever feasible. Patients were followed up at monthly intervals till patient is completely recovered. CXR was repeated at the end of treatment. Malnutrition was classified according to Indian Academy of Pediatrics IAP classification ${ }^{3}$. Complete recovery defined by weight gain, subsidence of the symptoms and signs, radiological improvement and improvement in the nutritional status at the end of the treatment. All these information and type of tuberculosis and follow up details were recorded in the proforma. Fisher exact test was used to test the significant difference between the proportions. The data were analyzed using SPSS software (SPPS, Chicago, IL). The ethical consent for the study was taken from the Institutional Review Committee, Kathmandu University School of Medical Sciences.

\section{Results}

During the study period 3152 patients were admitted. Sixty children had clinical and lab evidence of tuberculosis and received anti tubercular therapy. Fiftyfive were diagnosed to have probable tuberculosis while only five were confirmed bacteriologically. The overall prevalence of tuberculosis during the study period was $1.96 \%(60 / 3152)$ [95\% Cl 1.48-2.45]. Eighteen patients (30\%) were less than 5 years old; 21 patients (35\%) were 5-9 year old and 21 patients (35\%) were 10-15 year old. Mean age was $7.4 \pm 3.5$ years. There were more males $41(68.3 \%)$ than females $19(31.7 \%)$. Extra pulmonary tuberculosis was seen in $47(78.33 \%)$ and pulmonary tuberculosis in 13 patients (21.7\%). Among extra pulmonary tuberculosis the most common diagnosis was disseminated tuberculosis 25(41.7\%) followed by abdominal tuberculosis seven (11.7\%). Among pulmonary tuberculosis primary complex was seen in $5(8.33 \%)$ and progressive primary disease in $8(13.33 \%)$. Spectrum of tuberculosis is shown in Table 1.

Table 1: Spectrum of types of tuberculosis seen in children.

\begin{tabular}{|l|c|}
\hline \multicolumn{1}{|c|}{ Type of Tuberculosis } & Number (\%) \\
\hline Pulmonary & $13(21.7)$ \\
\hline 1. Primary Complex & $5(8.33)$ \\
\hline 2. Progressive Pulmonary Disease & $8(13.33)$ \\
\hline Extra Pulmonary & $47(78.33)$ \\
\hline 1. Disseminated & $25(41.7)$ \\
\hline 2. Abdominal & $7(11.7)$ \\
\hline 3. Pleural Effusion & $6(10)$ \\
\hline 4. Central Nervous System & $2(3.33)$ \\
\hline 5. Lymph Nodes & $5(8.33)$ \\
\hline 6. Potts Spine & $1(1.7)$ \\
\hline 7. Hip Bone & $1(1.7)$ \\
\hline \multicolumn{2}{|c|}{ Total } \\
\hline
\end{tabular}

There were no significant association between age and extra pulmonary tuberculosis however age $<5$ years was significantly associated with pulmonary tuberculosis $(p<0.05)$. Fifty two children $(86.6 \%)$ had BCG scar, absent BCG vaccination was significantly associated with disseminated TB $(p<0.05)$ History of contact was present in only 20 cases (32.3\%). The duration of onset of symptoms prior to admission ranged from $0.47-4$ month, with the mean duration of 2.2 months. The most frequently seen symptoms were fever $39(65 \%)$, anorexia and weight loss $18(30 \%)$. On physical examination, hepatomegaly was seen in $27(45)$ $\%$ cases, splenomegaly $7(11.67 \%)$, lymphadenopathy $14(23.33 \%)$ and ascites $20(33.33 \%)$. Clinical profile of tuberculosis is shown in Table 2.

Malnutrition was present in $20(33.3 \%)$. There were more malnourished children with disseminated TB than in other diagnosis $(p<0.001)$. Mantoux test was positive in $29(48.3 \%)$. No significant association was found between malnutrition and results of Mantoux test. Chest X-ray revealed most common finding of hilar lymphadenopathy $16(23.3 \%)$, unilateral pleural effusion $14(23.3 \%)$, no significant finding $13(21.7 \%)$, 
consolidation nine (15\%), reticulonodular densities four $(6.67 \%)$, bilateral pleural effusion three $(5 \%)$ and military mottling one $(1.7 \%)$.

Isolation of AFB was possible only in five cases (8.3\%), three from lymphnode biopsy and two from sputum sample. Among five TB lymphadenitis cases FNAC revealed granulomatous lymphadenitis in four $(80 \%)$ cases.

Among 60 cases thirty six $(60 \%)$ were recovered completely with the primary regimen, $3(5 \%)$ who were diagnosed disseminated tuberculosis from outside on Category I was extended for 3 more months and was recovered. Two cases which were diagnosed as disseminated tuberculosis after ruling out malignancy by bone marrow had persistence of symptoms even after completion of ATT for total of 9 months hence HIV (human immunodeficiency virus) test was also performed but came out to be negative hence were referred to National Tuberculosis Centre.

Fifteen cases (25\%) failed to follow up, while four cases $(6.67 \%)$ expired. Out of which three were diagnosed as disseminated TB and one was tubercular meningitis. Outcome of tuberculosis children is shown in Table 3.

Table 2: Showing summary of clinical profile of tuberculosis in children.

\begin{tabular}{|c|c|c|c|c|}
\hline $\begin{array}{c}\text { Presenting } \\
\text { features }\end{array}$ & Symptoms & Number (\%) & Signs & Number (\%) \\
\hline Non-specific & $\begin{array}{l}\text { Fever } \\
\text { Anorexia and } \\
\text { Weight loss } \\
\end{array}$ & $\begin{array}{l}39(65) \\
18(30)\end{array}$ & $\begin{array}{l}\text { Malnourished } \\
\text { Lymphadenopathy }\end{array}$ & $\begin{array}{l}20(33.33) \\
14(23.33)\end{array}$ \\
\hline Abdominal & $\begin{array}{l}\text { Abdominal distension } \\
\text { Pain abdomen } \\
\text { Altered bowel habit }\end{array}$ & $\begin{array}{l}22(36.67) \\
19(31.67) \\
11(18.33) \\
\end{array}$ & $\begin{array}{l}\text { Hepatomegaly } \\
\text { Ascites } \\
\text { Splenomegaly } \\
\end{array}$ & $\begin{array}{c}27(45) \\
20(33.33) \\
7(11.67) \\
\end{array}$ \\
\hline Respiratory & $\begin{array}{l}\text { Chronic cough } \\
\text { Chest pain } \\
\text { Breathing difficulty } \\
\text { Hemoptysis } \\
\end{array}$ & $\begin{array}{c}28(46.67) \\
7(11.67) \\
6(10) \\
1(1.67) \\
\end{array}$ & Chest Signs & $25(41.67)$ \\
\hline Others & \begin{tabular}{|l|} 
Paraplegia \\
Seizure \\
Headache / vomiting \\
Pain in hip joint \\
\end{tabular} & $\begin{array}{l}2(3.33) \\
1(1.67) \\
1(1.67) \\
1(1.67) \\
\end{array}$ & Neck stiffness & $2(3.33)$ \\
\hline
\end{tabular}

Table 3: Study outcomes of children with tuberculosis.

\begin{tabular}{|l|c|c|c|c|c|c|c|c|c|c|}
\hline \multicolumn{1}{|c|}{ Outcome } & DTB & Pul TB & Abd TB & PI Eff & CNS TB & TB LN & Potts & Hip TB & Total & $\%$ \\
\hline $\begin{array}{l}\text { Cured with } \\
\text { primary } \\
\text { regimen }\end{array}$ & 12 & 11 & 2 & 5 & 1 & 5 & - & - & 36 & 60.0 \\
\hline $\begin{array}{l}\text { Cured with } \\
\text { extending } \\
\text { duration } \\
\text { of primary } \\
\text { regimen }\end{array}$ & 3 & - & - & - & - & - & - & - & 3 & 5 \\
\hline $\begin{array}{l}\text { Persistence } \\
\text { of symptoms } \\
\text { after } \\
\text { completing } \\
\text { ATT }\end{array}$ & 2 & - & - & - & - & - & - & - & 2 & 3.33 \\
\hline $\begin{array}{l}\text { Lost to } \\
\text { Follow Up }\end{array}$ & 5 & 2 & 5 & 1 & - & - & 1 & 1 & 15 & 25 \\
\hline Died & 3 & - & - & - & 1 & - & - & - & 4 & 6.67 \\
\hline
\end{tabular}

* DTB: Disseminated Tuberculosis, Pul TB: Pulmonary Tuberculosis, Abd TB: Abdominal Tuberculosis, PI Eff: Plueral Effusion, TB LN: Tuberculosis of the Lymph Nodes, Potts: Potts Spine, HIP TB: Tuberculosis of the Hip. 


\section{Discussion}

The extent of tuberculosis problem in children is a reflection of infectious pool of adult smear positive cases in the community. $21(35 \%)$ were in the $5-9$ years and $18(30 \%)$ were less than 5 years old. Study conducted in Bangalore by Vishwanatha $\mathrm{KG}^{5}$ reported $48.2 \%$ were in $5-9$ years age and $38.2 \%$ in $<5$ years. This indicates the high prevalence of childhood tuberculosis in the younger group. The probable reasons for this may be due to low resistance of the host, increased prevalence of malnutrition and close contact with the infected adults.

There has been a rise in the prevalence of tuberculosis throughout the world with propensity of extra pulmonary involvement ${ }^{6,7}$. In our study extra pulmonary tuberculosis was found to be higher $47(78.3 \%)$ than pulmonary tuberculosis $13(21.7 \%)$, similar to recent studies in tertiary centers where extra pulmonary TB comprises $51-78 \% \%^{8,9}$. In our study among Extrapulmonary TB disseminated tuberculosis was the commonest followed by abdominal tuberculosis, contradicting to other studies where TB lymph node was commonest followed by TB pleurisy ${ }^{10,11}$.

There were no significant association between age and the extra pulmonary tuberculosis however age $<5$ years was significantly associated with pulmonary tuberculosis. In the study done in Philippines in culture positive tuberculosis patients the distribution of pulmonary tuberculosis was not age related, but there were significantly more subjects in the younger age group $<5$ years old who had TB meningitis ${ }^{12}$. Eighteen (30\%) were malnourished. Study has shown malnutrition adversely affects the host's defense mechanism by suppressing cell mediated response to the infection ${ }^{13}$. In malnourished children there is a higher risk of a localized lesion to become progressive or generalized disseminated tuberculosis, because of poor immune response to infection. Malnourished children had more extra pulmonary tuberculosis $(p=0.05)$ and there were more malnourished children who had disseminated TB which was statistically significant. Fifty two (86.67\%) had received BCG, absent BCG scar was significantly associated with disseminated TB $(p<0.05)$. Study conducted by Vishwanatha $\mathrm{KG}^{5}$ comparing 89 BCG vaccinated and 23 unvaccinated children concluded that all types of TB occur in BCG vaccinated children and $22.5 \%$ progress to severe disseminated forms. A meta-analysis of 14 prospective BCG trials and 12 case control studies concluded that the average protective effects of BCG vaccine are $50 \%{ }^{14}$. Protection is higher for meningitis and disseminated disease than for pulmonary tuberculosis. This may explain the higher prevalence of disseminated TB in our study.
Among 60 cases only $20(32.3 \%)$ of the respondents, history of exposure to TB from immediate family member was elicited. Study in South Africa ${ }^{15}$ in culture confirmed childhood tuberculosis revealed only $49.5 \%$ had contact history. This may be due to social stigma attached to the disease of being not accepted by family member.

The diagnosis of the childhood TB presents a major challenge as it is complicated by the absence of practical "gold standard"16,17. Bacteriologic confirmation, the accepted gold standard is of limited use in the children because of the paucibacillary nature of their disease and poor bacteriologic yield. Most children already infected may not show any sign and symptoms at all even with significant abnormalities in the chest radiographs ${ }^{18}$. The diagnosis of tuberculosis in children from endemic areas depend mainly on clinical features and the subjective interpretation of the chest radiograph ${ }^{19,20}$.

The clinical presentation of TB in children takes many forms. The diagnosis in most case is still based on clinical evidence alone ${ }^{21}$.

Several studies showed cough, fever, loss of appetite, diarrhoea, vomiting, and weight loss are the most common symptoms in the children with TB, even in the culture positive cases $^{12,22-25}$. In our study also these symptoms were common. Our study revealed signs suggestive of generalized disease including lymphadenopathy, hepatomegaly and splenomegaly similar to study done by $M$. Burroughs et.al in culture positive tuberculosis cases ${ }^{25}$. Study done in Philippines $^{12}$ also revealed most common findings as lymphadenopathy(55.2\%), symptoms referable to gastrointestinal tract $(26.9 \%)$, central nervous system(17.9\%).

All the children were tested for Mantoux and only $48.3 \%$ showed positive results similar to other studies where it was reported to be $30-40 \% 8,9$. In endemic areas a positive Mantoux is not uncommon in randomly selected healthy children ${ }^{26}$ which limit its diagnostic value. No significant association was found between malnutrition and results of Mantoux. Study by Cherry Lyn ${ }^{12}$ in culture positive TB showed most common finding in chest $\mathrm{x}$-ray to be hazy densities $23.6 \%$ and cystic lucencies $21.8 \%$, no significant finding $21.8 \%$, mediastinal lymphadenopathy $5.4 \%$. In our study Chest X-ray revealed most common finding of hilar lymphadenopathy $16(23.3 \%)$, unilateral pleural effusion 14(23.3\%), no significant finding 13(21.7\%), consolidation nine (15\%). 
Bacteriological or histological confirmation has been reported to be $10-35 \%$ in studies at tertiary centers $^{8,9}$. In the present study the diagnosis was often based on the indirect evidence of infection as AFB could be demonstrated in only five (8.33) \% of the cases. Two $(3.33 \%)$ was in sputum AFB and AFB lymph node $3(5 \%)$. Study conducted by S.K Kabra ${ }^{9}$ in AIMS (India) among tuberculosis patients without conducting culture, AFB could be isolated in $11 \%$ and was more commonly in lymph node tuberculosis which was comparable to our study.

However study conducted in Philippines ${ }^{12}$ all culture positive tuberculosis patients AFB was isolated in $62.7 \%$ with common sources being gastric aspirate(44.8\%) and sputum (38.8\%) with older subjects $>5$ years was significantly associated with a positive AFB ( $p=0.024)$. This study highlights culture is mandatory in all patients in order to avoid over diagnosis of tuberculosis children especially in children though studies of childhood tuberculosis TB shows only $40-50 \%$ of cases are culture positive $^{12}$. Poor yield of AFB may be due to paucibacillary nature of the illness and poor sample collection due to inability to produce appropriate sputum sample. Only $32-40 \%$ of gastric aspirates from children with pulmonary TBN are culture positive. Only 5-13\% of gastric aspirate are AFB smear positive ${ }^{27}$. However in our study gastric aspirate could not demonstrate any AFB. Studies of childhood TB showed that only $40-50 \%$ of cases are culture proven ${ }^{12}$. Follow up among 45 cases showed $60 \%$ were completely recovered from the disease, three(5\%) who were diagnosed disseminated tuberculosis from outside on Category I was extended for three more months and was recovered, two (3.33\%) had persistence of symptoms even after completion of treatment. $6.67 \%$ died and $25 \%$ lost to follow up. Follow up studies done even in culture positive cases ${ }^{12}$ revealed $10.4 \%$ cured of disease, $38.8 \%$ improved and $13.4 \%$ expired and more than one third were lost to follow up.

Limitation of our study were lack of data on the HIV status especially in disseminated TB as HIV test was not done on all cases due to economic factor. Contact survey for establishing a definite evidence of TB in the family members couldn't be done.

\section{Conclusion}

Extra pulmonary tuberculosis is common with higher incidence of disseminated tuberculosis in our set up. Bacteriological yield is very low. Outcome of tuberculosis revealed $60 \%$ were completely recovered from the disease, $5 \%$ recovered while extending duration of primary regimen, $3.33 \%$ had persistence of symptoms even after completion of treatment. $6.67 \%$ died and $25 \%$ were lost to follow up.

\section{Acknowledgement: None \\ Funding: None. \\ Conflict of Interest: None. \\ Permission from IRB: Yes.}

\section{References}

1. Guidance for national tuberculosis programme on the management of tuberculosis in children $\mathrm{WHO} /$ HTM/ TB/2006.371.

2. Starke JR. Childhood tuberculosis: ending the neglect. Int J Tuberc Lung Dis 2002;6:373-374.

3. Meenakshi N Mehta. Protein energy malnutrition. In: Parthasarathy.IAP textbook of pediatrics; $3^{\text {rd }}$ ed, Jaypee Brothers Medical Publishers pvt Itd, 2006.120-138.

4. Late PM Udani, A Parthasarathy. Tuberculosis in childhood. In: Parthasarathy. IAP textbook of pediatrics; $3^{\text {rd }}$ edition, Jaypee brothers medical publishers ( $p$ ) Itd, 2006.206-230.

5. Spectrum of Tuberculosis in BCG vaccinated and unvaccinated children in Bangalore, India. Chestmed [serialonline] 2007 [cited in 2010 March 26] available from URL: http//www.priory.com/ respiratory_medicine/tuberculosis_in_children. htm.

6. Shafer RW, Kim DS, Weiss JP, Quale JM. Extrapulmonary tuberculosis-patient with human immunodeficiency virus infection. Medicine (Baltimore) 1991;70:384-397.

7. Marais BJ, Gie RP, Schaaf HS, Hesseling AC, Enarsan DA, Beyers N. The spectrum of disease in children treated for tuberculosis in a highly endemic area. Int. J Tuberc Lung Dis 2006;10:732-738.

8. Vijaysekaran D, Kumar RA, Gowrishankar NC, et al. Mantoux and contact positively in tuberculosis. Indian J Pediatr 2006; 73:989-93.

9. Kabra SK, Lodha R, Seth V. Category based treatment of tuberculosis in children. Indian Pediatr 2004;41:927-37.

10. Sharma S, Sarin K, Khalid U.K, Singla N, Sharma P.P and Behera. D. Clinical profile and treatment outcome of tubercular pleurisy in pediatric age Group using DOTS strategy. Indian J Tuberc 2009;56:191-200. 
11. Villegas MV, Labrada LA, Saravia NG. Evaluation of polymerase chain reaction adenosine deaminase, and interferon- gamma in pleural fluid for the differential diagnosis of pleural tuberculosis. Chest

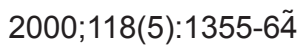

12. Cherry Lyn P. Pama, salvacion R. Gatchalian. Clinical Profile of culture- Proven tuberculosis cases among Filipino children aged 3 months to 18 years. Phil J Microbiol Infect Dis 2001; 30(4):133143.

13. Tupasi TE, Tadhakrisna S, Pascual ML, et al. BCG coverage and the annual risk of tuberculosis infection over a 14-year period in the Philippines assessed from the nationwide prevalence surveys. Int J Tuberc Lung Dis 2000;4(3):216-222.

14. Colditz G, Brewer T, Berkey C, et al. Efficacy of BCG vaccine in the prevention of tuberculosis: Meta-analysis of the published literature. JAMA 1994;271:698-702.

15. Cultured- confirmed childhood tuberculosis in Cape Town, South Africa a review of 596 cases. BMC Infect Dis 2007;7:140.

16. Starke JR. Childhood tuberculosis: a diagnostic dilemma. Chest 1993;104:329-330.

17. Eamranond $P$, Javamillo E. Tuberculosis in children: reassessing the need for improved diagnosis in global control strategies. Int $J$ Tuberc Lung Dis 2001; 5:594-603.

18. Donald PR. Childhood tuberculosis:out of control? Curr Opin Pulm Med 2002;8:178-182.

19. Weismuller MM, Graham SM, Claesens NJ, Meijnen S, Salaniponi FM, Harries AD. Diagnosis of childhood tuberculosis in Malawi: an audit of hospital practice. Int J Tuberc Lung Dis 2002;6:432438.

20. Enarson PM, Enarson DA, Gie RP. Management of tuberculosis in children in low-income countries. Int J Tuberc Lung Dis 2005;9:1299-1304.

21. Starke JR, Taylor Watts KT. Tuberculosis in pediatric population of Houston, Texas. Pediatrics 1989;84:28-35.

22. Vallejo JG, Ong LT, Starke JR. Clinical features, diagnosis and treatment of tuberculosis in infants. Pediatrics 1994; 94(1):1-7.

23. Kim JH, LangstonAA, Gallis HA. Miliary tuberculosis: epidemiology, clinical manifestations, diagnosis and outcome. Rev Infect Dis 1990;12(4):583-590.

24. Hussey G, Chisholm T, Kibel M. Miliary tuberculosis in Children: a review of 94 cases. Pediatr Infect Dis J 1991;10(11):832-836.

25. Burroughs M, Beitel A, Kawamura A, et al. Clinical presentation of tuberculosis in culture-positive children. Pediatr Infect Dis J 1999;18(5):440-446.

26. Obihara CC, Kimpen JL, Gie RP, Lill SW, Hoekstra MO, Marais BJ, Schaaf HS, Lawrence K, Potter PC, Bateman ED, et al. Mycobacterium tuberculosis infection may protect against allergy in a tuberculosis endemic area. Clin Exp Allergy 2006;36:70-76.

27. Smith KC, Starke JR, Eisenbach K, et al. Detection of a Mycobacterium Tuberculosis in clinical specimens from children using polymerase chain reaction. Pediatrics 1996;97:155-160.

\section{How to cite this article?}

Shrestha S, Marahatta SB, Poudyal P, Shrestha SM. Clinical Profile and Outcome of Childhood Tuberculosis at Dhulikhel Hospital. J Nepal Paedtr Soc 2011;31(1):11-16. 